www.neuropsychopharmacology.org

\section{Obituary Lee N Robins}

Neuropsychopharmacology (2010) 35, 2649;

doi: $10.1038 / n p p .2010 .65$

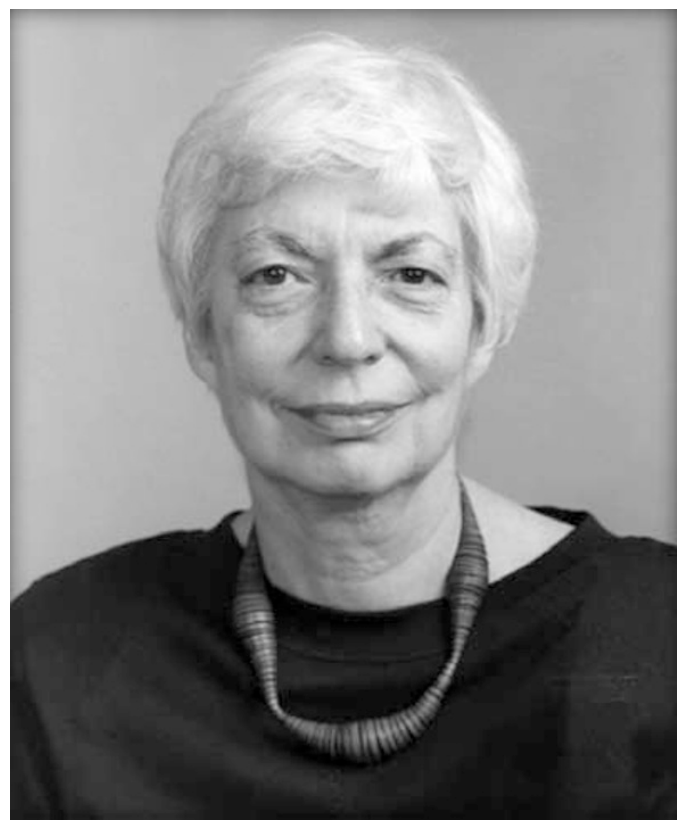

On 25 September 2009, Lee Nelken Robins, PhD, lost her long bout with colon cancer. She was 87 . She was professor emeritus of social science in psychiatry at Washington University School of Medicine in St Louis. She was also a highly esteemed psychiatric researcher with a long and influential career. Robins was elected to the ACNP in 1967 and was a life fellow at the time of her death.

Robins was born in New Orleans on 29 August 1922, and earned her doctoral degree in 1951, from Harvard University/Radcliffe College. She began her career at Washington University School of Medicine as a research assistant in the Department of Psychiatry, and was promoted to full professor in 1968. She founded and directed the unique Master's Program in Psychiatric Epidemiology, still in existence at the School of Medicine. She was also active on the undergraduate campus, where she held several positions through the years: lecturer and adjunct associate professor of sociology from 1957 to 1963, professor of sociology from 1969 to 1991, and professor in the Program for Social Thought and Analysis, beginning in 1991 until she retired in 2001.

Her research placed her at the forefront of psychiatric epidemiology research, with a career spanning five decades. Her early work focused on the effect of psychiatric disorders occurring in childhood on later adult life, spawning her seminal work, Deviant Children Grown Up, published by Williams \& Wilkins in 1966. Later NIH-funded studies looked at other populations, such as Vietnam veterans and disaster survivors, but it is the pioneering Epidemiologic Catchment Area study conducted in the 1980s with which she is perhaps most associated. She and principal investigators at other sites led this monumental study investigating the prevalence of psychiatric illness among the general population, for which 20000 people were interviewed. Robins wrote the Diagnostic Interview Schedule and, indeed, was a leader in the development of psychiatric assessments, training researchers from throughout the world in interview administration.

Robins achieved numerous distinctions in her career, including fellow of the American Academy of Arts and Sciences, fellow of the Society for the Study of Addiction to Alcohol and Other Drugs, member of the Institute of Medicine, the Paul Hoch Award from the American Psychopathological Association, the Nathan B Eddy Award from the College on Problems of Drug Dependence, the Lifetime Achievement Award from the Alcohol, Tobacco and Other Drugs section of the American Public Health Association, honorary fellow of the Royal Society of Psychiatrists and of the American Society of Psychiatrists, and the 2005 honorary grand marshal at the university's commencement.

In addition to her prolific and significant work, she and her husband Eli had four sons, eight grandchildren, and two great grandchildren. Robins was widowed in 1994, but she remarried in 1998, to Hugh Chaplin, Jr, MD, emeritus professor in Washington University School of Medicine's Departments of Medicine and Pathology and former head of the Irene Walter Johnson Institute of Rehabilitation.

Theodore J Cicero ${ }^{1}$ and Linda Cottler ${ }^{1}$ ${ }^{1}$ Department of Psychiatry, Washington University, St Louis, MI, USA 